\title{
CARACTERIZAÇÃO DA AMOSTRA DE PACIENTES ATENDIDOS NA UNIDADE DE TRANSPLANTE RENAL DA DIVISÃO DE CLÍNICA UROLÓGICA DO HCFMUSP NO PERÍODO DE DOIS MESES
}

\author{
Characterization of the sample of patients under care in the Renal Transplant Unit \\ of the Division of Urologic Clinic of HCFMUSP along two months
}

Dnyelle Souza Silva, Luiz Estevam lanhez

\begin{abstract}
RESUMO
Objetivo: Caracterização da população atendida na Unidade de Transplante Renal da Divisão de Clínica Urológica do HCFM USP e delimitação do perfil sócio-demográfico desses pacientes. Métodos: aplicação de questionário estruturado a pacientes que permaneceram na enfermaria da Unidade de Transplante Renal no período de dois meses. A nálise de porcentagem dos dados obtidos. Resultados: A diversidade sócio-demográfica do Estado de São Paulo pareceu coincidir com a da amostra da população atendida pelo Serviço da Unidade de transplante renal. R evelando a complexidade da caracterização desses pacientes muitas vezes oriundos de outros estados e com culturas diferentes. Conclusão: Há ainda muito a ser investigado em relação ao atendimento oferecido ao portador de insuficiência renal crônica que busca o transplante renal como tratamento.
\end{abstract}

Desaritores: D oença Crônica, Transplante Renal, A spectos Psicossociais, M igração.

Instituição:

Divisão de Psicologia e Unidade de Transplante Renal da Divisão de Clínica Urológica do HC/FMUSP

\section{Correspondência:}

Dnyelle Souza Silva

Avenida Dr.Éneas de Carvalho Aguiar, $255-7^{\circ}$ andar - sala $706 \mathrm{~F}$

CEP 05403-900 - São Paulo/SP - Brasil

Tel/fax: 5511 3069-6000

E-mail:yelless@yahoo.com.br

Recebido em: 26.04.2006

Aceito em: 31.05 .2006

\section{INTRODUÇÃO}

0 presente estudo foi realizado na enfermaria da Unidade de Transplante renal da Divisão de Clínica U rológica do HCFM USP, com o objetivo de alcançar uma amostra da população atendida no serviço e caracterizá-la conforme sua situação sócio-demográfica.

Entender de onde vêm eo que fazem esses pacientes pode auxiliar os profissionais a delimitar o serviço of erecido e ampliar perspectivas em relação à demanda da população assistida pela instituição.

0 primeiro transplante renal realizado no Brasil aconteceu em 1965, na Unidade de Transplante Renal do Hospital das Clinicas da Faculdade de M edicina da U niversidade de São Paulo. ${ }^{1}$

0 transplante renal tem como objetivo possibilitar uma melhor qualidade de vida ao indivíduo com insuficiência renal crônica (ICRT) e aumentar as chances de utilização de uma dieta mais próxima do normal, assim como possibilitar um resgate de perdas e trocas de papéis ocasionados pelo início do tratamento dialítico. 0 transplante pode ainda promover a reinserção do paciente ao meio social, fazendo com que o perceba como uma cura. Porém, o transplante é um método terapêutico que necessitará de acompanhamento médico e uso de medicamentos imunossupressores enquanto o paciente viver. A percepção do paciente a respeito do transplante é uma questão que aponta para a importância da orientação da equipe de saúde, oferecendo suporte e informações ao paciente durante 0 tratamento. ${ }^{1}$ 
A tualmente, há um consenso científico a respeito do transplante renal, considerando-o a melhor opção terapêutica para o paciente com insuficiência renal crônica terminal (IRCT) do ponto de vista clínico, social e econômico. 0 transplante renal é indicado quando a fase terminal da ICRT prevalece, mesmo o paciente estando em hemodiálise ou em fase pré-dialítica.

A Unidade de Transplante Renal (UTR) oferece dois programas de Tx: um com doador vivo (DV) e outro com doador falecido. Os doadores vivos podem pertencer a dois grupos distintos: 0 de doadores vivos relacionados (DV R) que apresentam laços sanguíneos de parentesco até segundo grau, tais como: pais, irmãos, primos, avós e doadores vivos não-relacionados que apresentam apenas laços afetivos com o receptor (ex: esposa, amigo).

Também pode ocorrer serem pessoas sem nenhum vínculo afetivo com o receptor que se candidata ao programa; estes merecem uma atenção especial durante a avaliação psicológica, com o objetivo de investigar as reais motivações que envolvem 0 ato de doar. ${ }^{1}$

A Unidade de Transplante renal da Divisão de Clínica U rológica do HCFM U SP possui um total de 20 leitos que atendem demandas diversificadas: desde a função prioritária de transplantes de doador-vivo até doador falecido, até enfermidades correlacionadas com o pós-transplante.

\section{OBJETIVOS}

Objetivo específico: Caracterização da população atendida na Unidade de Transplante renal da Divisão de Clínica U rológica do HCFM USP e delimitação do perfil sócio-demográfico desses pacientes.

Objetivo secundário: A partir dos dados obtidos, fazer uma comparação dessa amostra com a realidade populacional de São Paulo a fim de observar se a UTR atende à diversidade populacional do município.

\section{MÉTODO}

Foi elaborado um questionário estruturado com perguntas a respeito da idade, sexo, estado civil, grau de escolaridade, naturalidade, residência atual, data de diagnóstico de IRC, tempo de hemodiálise, transplante de doador-vivo ou doador falecido, tratamento fora de domicílio (TFD) ou qualquer auxílio do município, trabalho e fontes de renda (auxílio doença, aposentadoria e isenção de renda). 0 questionário foi aplicado no período de novembro e dezembro de 2006 por um mesmo profissional da área de Psicologia, sendo realizado um "rapport" antecedente à aplicação. A alta rotatividade de pacientes permitiu atingir 50 pacientes nesse período. 0 questionário encontra-se em anexo.

\section{RESULTADOS}

Foram entrevistados 50 pacientes no leito da enfermaria da UTR, sendo 25 do sexo masculino e 25 do sexo feminino.

A idade variou de 13 a 73 anos, sendo que houve dois (4\%) pacientes entre 13-20 anos, dezessete (34\%) pacientes de 21-40, trinta e um (62\%) pacientes de $41-70$. Esses dados revelam que a maior parte da amostra ainda se encontra em idade produtiva, o que nos parece relevante, se pensarmos na capacidade laborativa dos pacientes.

E m relação ao estado civil, foi predominante o número de pacientes que se denominaram casados $26(52 \%)$, seguido de dezoito soltei ros (36\%), cinco (10\%) divorciados e um viúvo (2\%).

Com relação à escolaridade, obtivemos maior porcentagem de pacientes com primei ro grau completo ou incompleto, 32 (64\%); o restante variou entre $14(28 \%)$ com segundo grau completo ou incompleto, três (6\%) com terceiro grau completo e um (2\%) analfabeto.

A naturalidade dos pacientes é relevante, pois a maioria dos pacientes atendidos no serviço não é nascida no estado de São Paulo (52\%), o restante da amostra é natural do interior ou da capital de São Paulo (48\%) (Ver Tabela 1).

Conforme podemos observar na Tabela 1, a maioria dos pacientes da amostra era natural do estado de São Paulo (interior ou capital), no entanto, podemos notar na Figura 1, que a região nordeste houve uma porcentagem significativa na migração para o município de São Paulo.

Tabela 1: Estado de origem dos pacientes atendidos na enfermaria da Unidade de Transplante Renal no período de novembro e dezembro de 2006.

\begin{tabular}{lcc}
\hline Local & N & Porcentagem \\
\hline SP & 13 & $26 \%$ \\
SP interior & 11 & $22 \%$ \\
RJ & 2 & $4 \%$ \\
MG & 5 & $10 \%$ \\
MS & 1 & $2 \%$ \\
BA & 7 & $14 \%$ \\
PE & 3 & $6 \%$ \\
CE & 1 & $2 \%$ \\
MA & 1 & $2 \%$ \\
PR & 1 & $2 \%$ \\
AM & 1 & $2 \%$ \\
PA & 1 & $2 \%$ \\
Outro país & 3 & $6 \%$ \\
\hline Total & 5 & \\
\hline
\end{tabular}

Figura 1: Dados referentes à amostra de pacientes oriundos das regiões responsáveis pela migração para o município de São Paulo

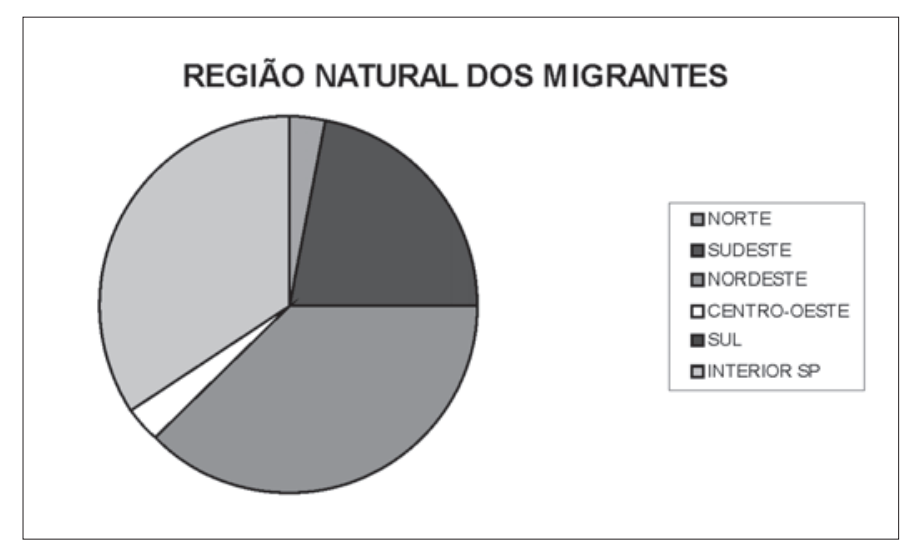


Observando o local de residência, podemos notar que a maioria dos pacientes atendidos no serviço reside no estado de São Paulo $41(82 \%)$. Porém, apenas $60 \%$ deles residem na capital do estado; os outros $32 \%$ residem no interior. D entre os pacientes que residem em outro estado, foi relatado que um mora em $M$ inas Gerais $(2 \%)$, um no Rio de Janeiro ( $2 \%)$, um no A mazonas $(2 \%)$ e um em Tocantins (2\%) (Figura 2).

O TFD é um Programa do SUS destinado a pessoas que necessitam de tratamento especializado não disponível na localidade de origem. ${ }^{2} 0$ paciente é encaminhado pelo médico da Rede Pública onde reside, para um centro de maior recurso, cuja localização seja mais próxima de sua cidade de origem. Geral mente, tem como ponto de referência a capital do Estado.

O TFD era desconhecido pela maioria dos pacientes (90\%), havendo apenas cinco pacientes (10\%) que se beneficiavam do auxílio para migrarem até o hospital (Tabela 2).

Tabela 2: Situação sócio-econômica da amostra

$\begin{array}{llllll}\text { Amostra } & \text { TFD } & \text { Trabalho } & \text { Renda } & \text { Auxílio Doença } & \text { Aposentadoria } \\ \text { SIM } & 5(10 \%) & 16(32 \%) & 37(74 \%) & 11(22 \%) & 15(30 \%) \\ \text { NÃ0 } & 45(90 \%) & 34(68 \%) & 13(26 \%) & 39(88 \%) & 35(70 \%)\end{array}$

Figura 2: Dados referentes ao local de residência da amostra de pacientes atendidos na Unidade de Transplante Renal no período de nov/dez de 2006.

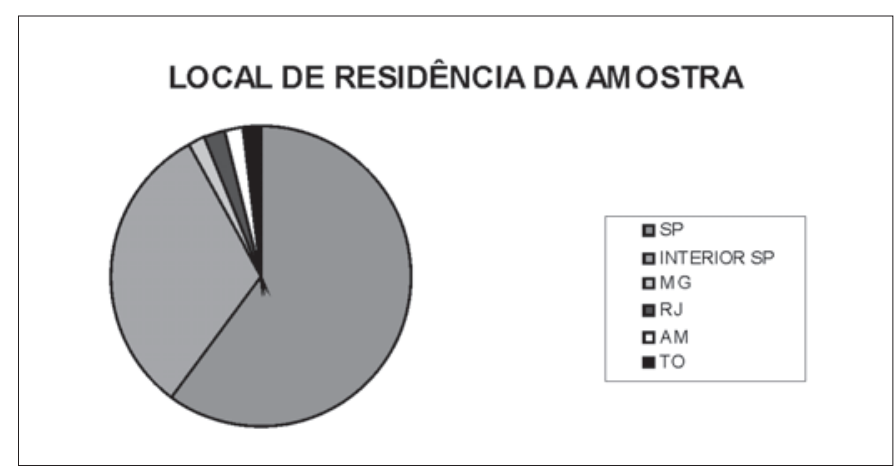

Com relação ao trabal ho, foi interessante observar que apenas dezesseis (32\%) pacientes estão inseridos no mercado de trabal ho, desenvolvendo atividades formais e informais. Os restantes 34 pacientes não trabal ham, atingindo $68 \%$ da amostra.

D ados rel ativos à renda do paciente foram organizados em tópicos: auxílio doença, aposentadoria e sem renda. A penas 11 pacientes (22\%) disseram receber auxílio doença. 0 restante não possui 0 auxílio, perfazendo $88 \%$ da amostra. A aposentadoria foi subdividida por idade ou por doença. Treze pacientes possuíam aposentadoria devido à doença $(26 \%)$ e apenas dois haviam se aposentado por idade (10\%); o restante dos pacientes (70\%) não havia conseguido se aposentar. Porém, 13 (26\%) pacientes não possuíam nenhum tipo de renda, o que nos surpreendeu, pelo fato de muitos dizerem desconhecer a possibilidade de receber auxílio ou mesmo não terem conseguido aposentadoria. A realidade sócio- econômica desses pacientes aponta para nível de renda restrito acentuadamente para uma única pessoa da família, responsável pela manutenção das despesas. (Tabela 2).

0 diagnóstico de insuficiência renal variou de 2000 a 2005, sendo que quatro (2\%) pacientes não recordavam da época do diagnóstico. G rande parte dos pacientes obteve 0 diagnóstico em anos anteriores a 2000 (52\%) e vinte pacientes o receberam entre 2001 e 2005 (40\%) (ver Tabela 3).

O tempo de hemodiálise foi diversificado, prevalecendo pacientes com um período de um a cinco anos de tratamento (54\%), seguidos de pacientes com seis anos ou mais ( $26 \%$ ) e apenas cinco pacientes com até um ano de hemodiálise (10\%).

0 tipo de transplante predominante nesse período foi o de doador vivo com 28 pacientes transplantados (56\%); entre eles, sete (14\%) haviam sido transplantados até 2000, dois (4\%) entre 2001 a 2005 e 19 (38\%) haviam sido transplantados em 2006. Dos pacientes transplantados com doador-cadáver (44\%), dois (4\%) haviam transplantado até 2000, cinco (10\%) entre 2001 a 2005 e 15 (30\%) haviam sido transplantados em 2006.

Foi perguntado porque os pacientes vieram transplantar no Hospital das Clínicas, e 26 pacientes (52\%) responderam que vieram por indicação do centro de diálise, oito (16\%) pacientes relataram não haver serviço de transplante no estado ou cidade onde residem, cinco (10\%) pacientes disseram que já estavam

Tabela 3: Dados da doença

\begin{tabular}{cccc}
\hline IRC & $\mathbf{N}(\%)$ & Tempo de HD & $\mathbf{N}(\%)$ \\
Até $\mathbf{2 0 0 0}$ & $26(52 \%)$ & $\mathbf{0}$ a $\mathbf{1}$ ano & $5(10 \%)$ \\
$\mathbf{2 0 0 1}$ a $\mathbf{2 0 0 5}$ & $20(40 \%)$ & $\mathbf{1}$ a $\mathbf{5}$ anos & $27(54 \%)$ \\
Não responderam & $4(8 \%)$ & $\mathbf{6}$ anos & $13(26 \%)$ \\
& & Não soube dizer & $5(10 \%)$ \\
\hline Total & 50 & Total & 50 \\
\hline
\end{tabular}

Tabela 4: Dados comparativos entre a amostra da Unidade de Transplante Renal e da Seade com relação aos migrantes

\begin{tabular}{lll}
\hline Migrantes & N $/$ UTR & SEADE (\%) \\
\hline SP interior & $11(22 \%)$ & $23,2 \%$ \\
RJ & $2(4 \%)$ & $3,7 \%$ \\
MG & $5(10 \%)$ & $9,4 \%$ \\
MS & $1(2 \%)$ & $0,9 \%$ \\
BA & $7(14 \%)$ & $29,5 \%$ \\
PE & $3(6 \%)$ & $12,9 \%$ \\
CE & $1(2 \%)$ & $7,5 \%$ \\
MA & $1(2 \%)$ & $3,4 \%$ \\
PR & $1(2 \%)$ & $4 \%$ \\
AM & $1(2 \%)$ & \\
PA & $1(2 \%)$ & $1,2 \%$ \\
\hline Total & $50(100 \%)$ & $100 \%$ \\
\hline
\end{tabular}


em tratamento no $\mathrm{HC}$ e um $(2 \%)$ paciente veio através de encaminhamento de outro hospital. Oito (16\%) pacientes disseram ter vindo por confiança no serviço prestado pelo hospital , um (2\%) através de amigo que conseguiu a vaga e um $(2 \%)$ disse que veio porque não podia pagar um serviço particular.

\section{DISCUSSÃO}

Foi interessante observar que a amostra da população atendida pelo serviço de transplante renal do Hospital das Clínicas de São Paulo é muito semelhante à população característica da cidade de São Paulo.

A diversidade da população que reside na capital revela uma situação sócio-demográfica típica de um centro que acolheu imigrantes de todas as regiões do país que vieram em busca de melhores condições de trabalho.

$\mathrm{Na}$ base de dados da Fundação Seade ${ }^{1}$ foi encontrado um levantamento da população de migrantes do município de São Paulo no período de 1995/2000, observando que 5,1\% da população total do município eram migrantes, sendo que 1,2\% veio de outros municípios do estado de São Paulo, e 3,9\% de outros estados. É importante ressaltar que foram consideradas migrantes, as pessoas com mais de cinco anos de idade, cuja U F de residência em uma data fixa (definida pelo censo) era distinta daquela em que residiam no momento do censo (31/07/1995). Esses dados conferem com a amostra da população atendida na UTR do HCFM USP, que apresentou uma porcentagem expressiva de migrantes de outros estados e do interior do estado de São Paulo, como pôde ser observado nos resultados. ${ }^{3}$

A fundação Seade e o IBGE também fizeram levantamento dos migrantes residentes segundo o local de origem no município de São Paulo, no período de 1995/2000. A porcentagem de migrantes oriundos de outros municípios do Estado de São Paulo representou 23,2\% da população analisada, e 76,8\% eram de outros estados brasileiros.

A região N ordeste foi a que forneceu maior número de migrantes para o município de São Paulo com $71,8 \%$ da população, e a Bahia foi o estado com maior prevalência de migrantes, com cerca de $29,5 \%$, seguido de Pernambuco, com $12,9 \%$. A região Sudeste foi responsável pela segunda maior porcentagem de migração, $14 \%$, tendo o estado de $\mathrm{M}$ inas Gerais 9,4\% desses migrantes. A região Sul teve uma contribuição de $6,7 \%$ dos migrantes, tendo o Paraná $4 \%$ desta parcela. A região CentroO este $3,4 \%$, 0 estado de $\mathrm{G}$ oiás teve $1,1 \%$ dessa população. A região N orte $2,3 \%$ sendo o Pará o estado com maior porcentagem dessa região 1,2\% (ver Tabela 4 ). ${ }^{4}$

Os dados acima (Tabela 4) confirmam a amostra encontrada no levantamento real izado na U TR, e permite-nos entender a situação dos pacientes atendidos pelo serviço oferecido pelo Hospital das Clínicas, considerado por muitos como centro de referência para o país inteiro. Podemos observar que a congruência dos dados obtidos externamente pela Seade, assi m como internamente pelo serviço da UTR, revelam uma tendência de décadas anteriores à atual, pois levantamentos recentes revelam que a migração no estado de São Paulo está se caracterizando por um número de pessoas saindo do estado.

A transformação no mundo do trabal ho é a grande responsável pela "migração de retorno". A diminuição de emprego na indústria e na construção civil vem diminuindo, e esses eram exatamente os setores que tradicionalmente absorviam mão-de-obra pouco qualificada. A priorização do trabalho voltada para o setor de prestação de serviços também pode ser responsável pelo fluxo inverso dos migrantes em São Paulo. ${ }^{5}$

Parece interessante pensar que o transplante na UTR do $\mathrm{HC} /$ FM USP determina a migração de pacientes de outros estados, pois a conti nuidade do tratamento à distância parece complicada, se analisarmos que tratamos pacientes com comorbidades, e a própria imunossupressão torna-os suscetíveis a outras manifestações de doenças.

O estado da Bahia possui apenas uma central de transplantes, o que parece justificar a grande porcentagem de pacientes que buscam o serviço da UTR. A liás, todos os estados do Nordeste possuem apenas uma central em cada um deles. No A mazonas não existe nenhuma central cadastrada. ${ }^{6}$ É interessante pensar que o estado de $\mathrm{M}$ inas Gerais possui cerca de oito centrais registradas, e, no entanto, foi o segundo maior responsável pela migração de pacientes para o serviço da UTR. Esses dados nos fazem questionar porque esses pacientes buscam o transplante no HCFM USP, pois sabemos que há muitos anos a migração para o estado de São Paulo era recorrente, sendo o trabalho o maior motivador desse processo. Vinham, ainda, em busca de tratamento, por não possuírem recursos em seus estados. A gora, é preciso repensar a razão que faz com que tantos pacientes busquem tratamento fora de seu domicílio.

\section{CONCLUSÃO}

Diante dessa nova realidade e das condições inerentes à própria doença renal crônica, parece coerente 0 alto índice de desemprego encontrado no nosso levantamento. No entanto, é necessário repensar como cada indivíduo estabel ece sua relação com a doença e por que muitos deles não encontram formas de reinserção na vida social e no trabal ho. Fica aberta para novos estudos essa questão, assi m como tantas outras que abrangem a situação de ser paciente renal crônico no Brasil e no Hospital das Clínicas de São Paulo, serviço que atende uma população diversificada, podendo ser considerada uma amostra da população geral do País.

Este levantamento abre um campo para discussão que abrange a realidade sócio-econômica do País e, sobretudo, a atuação do profissional de saúde que acolhe tamanha diversidade sóciocultural no ambiente hospitalar.

\section{ABSTRACT}

Purpose: Features of the population under care in the Renal Transplant Unit of the Division of U rologic Clinic of the HCFM USP, and to circumscribe the social-demographic profile of those patients. Methods: A pplication of structuralized questionnai re to in-patients at the U nit of Transplant Renal's ward along a two months period. A nalysis of the percentage of the attained data. Results: The social-demographic 
diversity of the State of São Paulo seemed to coincide with the sample of the population under care in the Renal Transplant Service. Exposing the complexity of these patients' features, much of them coming from other states and with different cultures. Condusion: There is much yet to be investigated related to the service offered to the bearers of chronic renal failure in search for a renal transplant as treatment.

Keywords: Chronic disease, Kidney Transplantation, Psychosocial A spects, M igration.

\section{REFERÊNCIAS}

1. Ianhez, L. E. Transplante renal: aspectos clínicos e práticos. Produtos Roche. São Paulo: 2001.

2. Sistema Nacional de Auditoria. DENASUS - Departamento Nacional de Auditoria do SUS. Brasília (DF): Ministério da Saúde. [Acesso em 2007 Fev. 20]. Disponível em: http://sna.saude.gov.br/legisla/legisla/tfd/.

3. Fundação Sistema Estadual de Análise de Dados do Governo do Estado de São Paulo (SEADE). [Atualizada em 2006 Fev.; acesso em 2007 Fev. 08]. Disponível em: http://www.seade.gov.br.
4. Instituto Brasileiro de Geografia e estatística [base de dados na internet]. Brasília: Ministério do Planejamento, orçamento e gestão. [Acesso em 2007 Fev. 05]. Disponível em: http://www.ibge.gov.br

5. Nunes, C. Com Ciência Revista eletrônica de jornalismo científico. São Paulo: Sociedade Brasileira para o Progresso da Ciência (SBPC) [Atualizado em 2006 Fev. 07; acesso em 2007 Fev. 08]. Disponível em: www.comciencia.br/ noticias/2006/02/migracao.htm.

6. Centrais de Transplante [base de dados na internet]. São Paulo: Sociedade Brasileira de Nefrologia (SBN) [acesso em 2007 Fev.05] Disponível em: http:// www.sbn.org.br. 